\title{
A formação de professoras para o ensino de ciências nas séries iniciais: análise dos efeitos de uma proposta inovadora
}

\section{Training teachers to teach sciences in elementary school: an analysis concerning the effectiveness of an innovative approach}

Thaís Gimenez da Silva Augusto ${ }^{1}$. Ivan Amorosino do Amaral ${ }^{2}$

\begin{abstract}
Resumo: Pesquisa empírica que tem como objetivo analisar os efeitos de uma proposta inovadora de formação em serviço nas concepções e práticas declaradas de professoras polivalentes que lecionam Ciências nas séries iniciais. As professoras pesquisadas cursavam Licenciatura Plena em Pedagogia na Unicamp, por um convênio entre a universidade e as prefeituras municipais da Região Metropolitana de Campinas. Pesquisou-se quais as concepções e práticas declaradas, de 13 professoras, sobre o ensino de Ciências para as séries iniciais anteriormente, durante o transcorrer e ao final da disciplina, por meio de: questionários, redações, observação do curso e entrevistas. Concluiu-se que, embora a maioria das professoras pareça ter compreendido as ideias-chave da disciplina e tenha promovido mudanças em suas práticas docentes, a falta de conhecimento prévio de conteúdos específicos de Ciências e a pequena carga horária disponível foram os principais fatores que impossibilitaram a apreensão mais abrangente de algumas das ideias enfocadas pela disciplina.
\end{abstract}

Palavras-chave: Ensino de ciências. Formação de professores. Séries iniciais. Prática docente. Ensino Fundamental.

\begin{abstract}
This work is based on empirical research data and aims at analyzing the effectiveness of an innovative approach applied during the training of multipurpose teachers who teach sciences in primary schools. The researched teachers were studying Pedagogy at Unicamp due to an agreement among the university and city halls belonging to the metropolitan area of Campinas. The declared practices and ideas carried out by 13 teachers who teach sciences were researched. Previous data and information given during and at the end of the course through questionnaires, essays, observations and interviews was used. Although the majority of teachers seemed to have understood the key ideas of the course and promoted changes in their classes, it was concluded that the lack of previous knowledge, concerning specific science content, and the small number of hours available for teaching were the main factors which make it impossible for a wider apprehension of some ideas highlighted in the course to be present.
\end{abstract}

Keywords: Science teaching. Teachers training. Teaching practice. Elementary school.

\footnotetext{
${ }^{1}$ Faculdade de Ciências Agrárias e Veterinárias, UNESP - Univ Estadual Paulista, Via de acesso Prof. Paulo Donato Castellane, s/n, Zona Rural, CEP 14884-900, Jaboticabal, SP, Brasil. E-mail: <thaisgime@fcav.unesp.br>

${ }^{2}$ Faculdade de Educação, Universidade Estadual de Campinas (Unicamp), Campinas, SP, Brasil.
} 


\section{Introdução}

O ensino de Ciências desde as primeiras séries de escolaridade é fortemente preconizado no Brasil a partir da década de 1970, com a implantação da Lei 5.692, de 11 de agosto de 1971 (BRASIL, 1971), que estendeu a obrigatoriedade do ensino de Ciências a todas as séries do então denominado ensino de $1^{\circ}$. Grau e, hoje, Ensino Fundamental.

Desde então, essa perspectiva de valorização do ensino de Ciências vem sendo reiterada em várias instâncias. No tocante aos currículos atuais, os Parâmetros Curriculares Nacionais, no documento que se refere às séries iniciais do Ensino Fundamental, afirmam que: "Numa sociedade em que se convive com a supervalorização do conhecimento científico e com a crescente intervenção da tecnologia no dia-a-dia, não é possível pensar na formação de um cidadão crítico à margem do saber científico" (BRASIL, 1997, p. 23).

Paradoxalmente, os cursos de formação de professoras $^{3}$ para as séries iniciais do Ensino Fundamental destinam poucas horas para Ciências, produzindo uma formação insuficiente nessa disciplina (FREIRE, 2000; SILVA, 1998).

Até meados da década passada, um significativo contingente de professoras que atuam nessa etapa da escolarização tinha apenas formação de nível Médio, isto é, cursou o Magistério como habilitação para lecionar. Embora esses cursos não tivessem um currículo padronizado, geralmente, davam pouca ênfase às disciplinas científicas, e, quando o faziam, abordavam apenas suas metodologias de ensino. Portanto, a formação dessas professoras em conteúdos de Ciências era proveniente, em sua grande maioria, dos conhecimentos que haviam adquirido quando cursaram o Ensino Fundamental (DUCAT'TI-SILVA, 2005; FREIRE, 2000).

A Lei de Diretrizes e Bases da Educação (BRASIL, 1996), promulgada em 1996, instituiu a formação obrigatória em nível Superior para professoras que trabalham no primeiro e segundo ciclos do Ensino Fundamental, e que, anteriormente, estavam habilitadas a partir dos cursos de Magistério - Ensino Médio. A nova legislação fez com que muitos governos estaduais e municipais firmassem convênios com as Universidades para formar as professoras que já trabalhavam no Ensino Fundamental e não tinham graduação no ensino superior.

Com esse objetivo, uma parceria entre a Universidade Estadual de Campinas (Unicamp) e as Secretarias de Educação dos Municípios da região metropolitana de Campinas resultou no oferecimento de um curso de formação em Licenciatura Plena em Pedagogia denominado Programa Especial para Formação de Professores em Exercício na Rede de Educação Infantil e Primeiras Séries do Ensino Fundamental da Rede Municipal dos Municípios da Região Metropolitana de Campinas (PROESF). Tratou-se de um programa simultaneamente de formação inicial e de formação continuada, pois um dos requisitos para o ingresso era estar exercendo função docente na educação infantil ou nas séries iniciais do Ensino Fundamental.

Esse curso abrigava a disciplina Teoria Pedagógica e Produção em Ciências e Meio Ambiente, que teve uma abordagem inovadora ao privilegiar, entre outros aspectos, o ensino centrado nos fenômenos e se propor a auxiliar a professora a desvelar a Ciência e a revelar plenamente o ambiente (AMARAL, 2005). Em tese, a disciplina pôde contribuir para uma formação

\footnotetext{
${ }^{3}$ Utilizaremos a forma feminina pelo fato de a grande maioria, senão a quase totalidade das pessoas que lecionam nos primeiros ciclos do Ensino Fundamental, serem mulheres. 
diferenciada em Ciências para as professoras das séries iniciais do Ensino Fundamental e educação infantil, e promover mudanças em suas práticas pedagógicas. Pelo potencial de formação dessa disciplina, ela tornou-se o foco da presente pesquisa, cujo objetivo foi: caracterizar como as professoras das séries iniciais lidam com os elementos básicos de um currículo de Ciências atual e inovador, difundido pela disciplina Teoria Pedagógica e Produção em Ciências e Meio Ambiente, em um curso de formação em serviço de Licenciatura Plena em Pedagogia (PROESF).

Para atingir esse objetivo maior, buscou-se responder às seguintes questões:

- Quais as concepções e práticas pedagógicas declaradas sobre ensino de Ciências, apresentadas no início da disciplina pelas professoras pesquisadas?

- Após cursarem a disciplina em foco, ocorreram mudanças nas concepções e/ou nas práticas declaradas das professoras pesquisadas? Em que aspectos?

- Após cursarem a disciplina em foco, as concepções e/ou as práticas declaradas das professoras pesquisadas permaneceram iguais a antes de cursarem a disciplina? Em que aspectos?

- A que se podem atribuir as eventuais mudanças e as eventuais permanências nas concepções e/ou práticas declaradas das professoras participantes que cursaram a disciplina?

\section{Justificativa da pesquisa}

A formação de cidadãos críticos, capazes de compreender o mundo em que vivem e tomar decisões, é um dos principais objetivos educativos da escola atualmente. Nesse cenário, o ensino de Ciências, desde as séries iniciais, ganha importância na medida em que a Ciência e a Tecnologia estão cada vez mais presentes no cotidiano das pessoas (BRASIL, 1997).

A criança de seis a dez anos, faixa etária própria das séries iniciais, apresenta uma curiosidade natural em relação aos fenômenos do mundo físico e biológico com o qual interage cotidianamente. Contudo, as professoras dessa etapa da escolarização, polivalentes e generalistas, muitas vezes, encontram dificuldades para ensinar Ciências devido a sua formação com pouca ênfase nessa área. Privilegiam, amplamente, a alfabetização e o ensino de matemática por julgá-los mais relevantes (DELIZOICOV; ANGOTTI, 2000; MONTEIRO; TEIXEIRA, 2004; ROSA; PEREZ; DRUM, 2007; PAVAN; BRASIL; TERRAZZAN, 2007).

O tornar-se professor, aprender a profissão, é um processo contínuo em que o docente aperfeiçoa sua prática a partir de reflexões fundamentadas em teorias de cunho metodológico e conceitual. A necessidade de lidar com uma clientela cada vez mais plural do ponto de vista cognitivo, social, cultural, étnico e linguístico, exige dos professores um conhecimento mais maleável e atualizado dos conteúdos e de metodologias de ensino facilitadoras do aprendizado. Todavia, o ritmo acelerado diário e o excesso de trabalho em um ambiente complexo como a escola, com múltiplas variáveis em interação, faz com que restem, ao docente, poucas oportunidades de refletir sobre sua prática e analisar os problemas diários (MIZUKAMI, 1999). Engajando-se produtivamente nesse cenário, os cursos de formação inicial e continuada de professores devem ser um espaço que favoreça a reflexão individual e coletiva, o diálogo entre diferentes disciplinas e a construção de práticas de sala de aula embasadas por teorias sólidas de ensino/aprendizagem. Esses cursos devem, também, promover o encontro entre a pesquisa realizada nas Universidades e os professores inseridos nas escolas públicas de Ensino Fundamental e Médio (AUGUSTO, 2004). 
Delizoicov, Lopes e Alves (2005) e Silva (1998) apontam que as professoras dos primeiros ciclos do Ensino Fundamental reconhecem a necessidade da formação continuada para sanar as falhas da formação inicial. Todavia, os autores advertem sobre a necessidade de uma formação continuada que considere a prática pedagógica e os saberes docentes das professoras participantes:

De qualquer forma, é preciso, cada vez mais, enfrentar a questão da melhor relação entre aspectos formativos e atuação profissional. Se, por um lado, há a necessidade de uma articulação mais orgânica da formação inicial e a atuação profissional nos espaços escolares, também não é suficiente uma formação continuada que não esteja articulada organicamente ao cotidiano de atuação docente. (DELIZOICOV; LOPES; ALVES, 2005, p. 5)

A formação superficial ou deficiente para o ensino de Ciências ajudou a disseminar muitos mitos e equívocos entre as professoras das séries iniciais. Esses mitos e equívocos têm reflexo direto nas concepções e práticas pedagógicas dessas docentes.

Segundo Amaral (2005), entre as professoras das séries iniciais, é comum a crença de que, para se ensinar Ciências, é necessária a disponibilidade de laboratórios e materiais sofisticados. Acreditam que Ciências é uma disciplina difícil de ser ensinada, não apenas pelas limitações de sua formação, mas, sobretudo, porque a atividade científica seria desenvolvida por pessoas especiais, ou seja, por gênios. A ênfase na observação aliada à promoção de hábitos adequados de higiene e saúde são a tônica desse nível de escolaridade. Ademais, para o autor:

[...] sobrevive a idéia que considera papel primordial da Ciência a eliminação de todas as manifestações de senso comum no pensamento do aluno, substituindo-as pelo raciocínio científico. Quase como uma decorrência natural dessas imagens, emerge a idéia que preconiza a formação no aluno de uma atitude de reverência e de adesão acrítica diante da Ciência e da Tecnologia. (AMARAL, 2005, p. 83)

Esses mitos, em grande parte, foram difundidos pelo tecnicismo educacional, que marcou as inovações, nas décadas de 1960 e 1970, na educação brasileira nessa área, permanecendo até os dias atuais. O modelo de ensino de Ciências preconizado nesse período, denominado modelo da redescoberta, caracterizava-se pela exaltação da Ciência e da figura do cientista, pelo incentivo ao uso acrítico de laboratórios e a consequente ênfase na aprendizagem de um suposto método científico, na verdade, tão somente um método didático (AMARAL, 2005).

Para o autor em foco, com a preconização da educação ambiental pelos novos currículos, emergiu o mito de que os temas ambientais estariam relacionados apenas a Ciências, como provável decorrência de terem surgido com os estudos ecológicos ligados à Biologia. Em virtude disso, recebem, nas escolas, um tratamento predominantemente naturalista, isto é, os aspectos sociais e ideológicos ligados às questões ambientais, geralmente, não são abordados.

Portanto, os mitos, equívocos e conhecimentos assistemáticos que povoam o pensamento das professoras das séries iniciais do Ensino Fundamental geram concepções e práticas sincréticas sobre o ensino de Ciências. Essas concepções, somadas a uma formação inicial 
deficiente em Ciências, tendem a conflitar com os princípios e diretrizes programático-metodológicos inovadores que dão sustentação a alguns programas de formação continuada.

A importância do PROESF residiu no fato de oferecer, por um período relativamente longo e sistematicamente, formação inicial e continuada presencial para um grande número de professoras da região metropolitana de Campinas; e difundir resultados de estudos e pesquisas de diferentes grupos da Faculdade de Educação da Unicamp a respeito de currículos nas respectivas áreas da educação infantil e Fundamental. Em relação ao currículo de Ciências, considerava como um dos pontos de partida os mitos e equívocos presentes nas concepções dessas professoras, desenvolvendo-se a partir deles e buscando um novo paradigma para o ensino de Ciências no nível Fundamental da escolarização.

Segundo Amaral (1998), os modelos clássicos do ensino de Ciências (Tradicional e da Redescoberta), hoje obsoletos historicamente, vêm sendo colocados em questão já há algumas décadas. A disciplina Teoria Pedagógica e Produção em Ciências e Meio Ambiente foi idealizada por Amaral, e reuniu elementos curriculares - metodológicos e epistemológicos - propostos por pesquisadores e especialistas nos últimos 20 anos, incluindo as contribuições do Grupo de Estudo e Pesquisa Formar Ciências. Na busca por um novo paradigma para o ensino de Ciências, o autor enfatiza a necessidade de:

[...] articular operacionalmente todos os princípios e diretrizes curriculares recentemente preconizados, buscando uma nova maneira de integração entre forma e conteúdo, tendo o ambiente terrestre como o grande tema gerador, organizador e unificador do processo de ensino-aprendizagem [...], aliar o pensamento teórico à prática docente e assim engajar o professor de forma efetiva no processo de produção da mudança, na decantada linha da ação-reflexão-ação. (AMARAL, 1998, p. 221)

A proposição de centrar o currículo de Ciências nos fenômenos do Ambiente é fortemente preconizada pela disciplina em foco, que pretende revelar plenamente o ambiente, ou seja, não reduzir o estudo do ambiente apenas aos seus aspectos físicos e biológicos, mas considerar os fatores sociais, econômicos, políticos e culturais envolvidos, tornando a temática ambiental o eixo articulador do currículo (AMARAL, 2005).

O outro foco central da disciplina, enunciado como desvelar sinceramente a Ciência (AMARAL, 2005), está, em parte, contemplado no seguinte trecho de Carvalho (2001, p. 140):

Atualmente, quando se fala em objetivos que envolvem a compreensão sobre a 'natureza da ciência', pressupõe-se uma análise que inclui um componente crítico em relação ao processo científico. Enfatiza-se, agora, a necessidade de que todos os cidadãos se apropriem desta compreensão e se situem frente a esta discussão [...].

Para esse autor, os cursos de formação de professores e professoras devem abordar as questões relacionadas à natureza da Ciência, devido ao papel preponderante desses profissionais para a construção de uma visão crítica, em relação aos conhecimentos científicos, pelos estudantes. 
Todavia, para Amaral (2005, p. 86), desvelar a Ciência parece implicar a abordagem de outras dimensões, tais como:

[...] apresentar não somente os seus produtos (os conhecimentos por ela produzidos), como também revelar os teores de veracidade e certeza que os cercam, seus limites e possibilidades, os contextos históricos em que foram produzidos, suas relações com a tecnologia, seus usos práticos, seus danos e benefícios à sociedade e ao ambiente, suas relações com outras formas de conhecimento. Implica, ainda, não apenas revelar seus raciocínios e procedimentos mais típicos, como também mostrar as relações dos mesmos com o senso comum, realçando suas subjetividades e as influências que os cercam, desde a escolha do tema, a seleção dos problemas e das hipóteses a serem pesquisados até a formulação das conclusões. Trata-se, pois, de apresentar a ciência como atividade bumana, similar a tantas outras, com seus poderes e fragilidades, sucessos e insucessos, suas ambigüidades e incertezas, além de sua responsabilidade social e ética. Neste cenário, o cientista deve ser delineado como alguém semelhante a todos nós, com as habilidades e competências específicas de sua profissão. Ressalvadas as diferenças de circunstâncias e intensidades de manifestação, a atividade científica está sujeita também a ciladas semelhantes às de outras profissões, levando os cientistas a enganos, superficialidades e fragilidades nos resultados de suas pesquisas. Não é apenas o senso comum que se precipita, que é influenciado pela aparência das coisas, que conclui antes de observar cuidadosamente e investigar, que pula ou inverte etapas; a seu modo, o cientista também não segue procedimentos rígidos e também se equivoca nas suas conclusões; ou, mesmo quando acerta, comumente o faz por caminhos heterodoxos. (Grifo do autor)

Ademais, foi considerado, em todas as etapas do desenvolvimento da disciplina em foco, o saber docente das alunas participantes, e procurou-se promover intercâmbios de experiências entre as mesmas.

\section{O PROESF e a disciplina}

\section{Teoria Pedagógica e Produção em Ciências e Meio Ambiente}

O curso de graduação em Licenciatura Plena em Pedagogia do PROESF foi oferecido de 2002 a 2008. Tinha duração de três anos (três mil e trezentas horas). Era presencial e absorvia, anualmente, quatrocentas docentes ingressantes, oriundas de 19 municípios da Região Metropolitana de Campinas. Em 2008, o curso foi concluído pela sua quarta e última turma, perfazendo um total aproximado de um mil e seiscentas alunas-professoras envolvidas.

As aulas eram ministradas por Assistentes Pedagógicos (AP), professores das redes municipais com curso Superior, que foram preparados para o exercício dessa função por meio 
de um curso de especialização promovido pela Faculdade de Educação da Unicamp. Após cursar as disciplinas da especialização que eram equivalentes às que seriam ministradas no PROESF, o candidato a AP escolhia as disciplinas que gostaria de vir a ministrar. Uma vez selecionados, os AP passavam por um processo intensivo de elaboração das disciplinas a serem ministradas, sob a coordenação de docentes da Faculdade de Educação. Posteriormente, esses Assistentes Pedagógicos eram supervisionados, ao longo do curso, pelos mesmos docentes da Unicamp, que se tornaram responsáveis pela disciplina que eles ministravam. Durante toda a duração do PROESF, permaneceram como alunos do referido curso de especialização a fim de manterem o vínculo institucional com a Unicamp e, ao final do PROESF, produziram uma monografia de conclusão do curso.

A Faculdade de Educação da Unicamp coordenou o curso, e os supervisores, em conjunto com os Assistentes Pedagógicos, produziram o material didático do mesmo.

Havia apenas uma disciplina na estrutura do curso que contemplava a área de Ciências, cuja ementa está transcrita a seguir:

\section{PE402-Teoria Pedagógica e Produção em Ciências e Meio Ambiente Cidadania e finalidades do ensino de Ciências e Meio Ambiente no mundo contemporâneo. Controvérsias históricas no desenvolvimento do ensino de Ciências. Concepções de Educação, Ciência e Ambiente e suas influências no ensino de Ciências. Fundamentos teórico-meto- dológicos do ensino de Ciências e Meio Ambiente. Metodologia do Ensino de Ciências como produção social. Ensino e Pesquisa na prática pedagógica em Ciências. Meio Ambiente como tema transversal no ensino fundamental. Ensino de Ciências como educação ambiental. (UNIVERSIDADE ESTADUAL DE CAMPINAS, 2006)}

A disciplina em questão tinha carga horária de sessenta horas e era ministrada no quarto semestre do curso. Baseava-se em sete ideias-chave de cunho programático e metodológico, assim designadas por Amaral (2005, p. 86-92):

1. Ciência como atividade humana;

2. Ambiente em transformação, interação, integração e equilíbrio dinâmico;

3. Universalidade das transformações e uniformidade dos processos no ambiente terrestre;

4. Indissociabilidade entre os mundos natural e humanizado;

5. Problematização dos conteúdos e formulação de hipóteses;

6. Incorporação dos universos físico, social, cultural e psicológico do aluno;

7. Estímulo ao desenvolvimento do pensamento crítico e divergente.

A primeira ideia-chave propõe a compreensão da Ciência como atividade humana, o que significa desmitificá-la, percebê-la não como uma atividade neutra, mas, sim, sujeita a subjetividades, interesses políticos e econômicos, bem como em estreita relação com a sociedade. 
As três ideias-chave seguintes $(2,3,4)$ relacionam-se à noção de ambiente. Focam no conceito de transformação como um fenômeno comum aos mundos físico, biológico e social. Os fluxos de energia associados a essas transformações provocam mudanças o tempo todo e em todo lugar, e são responsáveis pelo equilíbrio dinâmico do planeta. Essas mudanças interagem e se integram em diversas escalas espaço-temporais. O ser humano age sobre o ambiente e este sobre ele, pois é parte integrante do mesmo, o que denota a impossibilidade de separar o mundo humanizado do natural.

As ideias-chave 5, 6 e 7 têm caráter predominantemente metodológico, e mostram a intenção da disciplina em questão de proporcionar, às professoras, uma formação voltada para um ensino ativo, que abranja as concepções prévias e o cotidiano do aluno, e que não negligencie suas fases de desenvolvimento psicossociocognitivo. A problematização, o estímulo à formulação de hipóteses e ao pensamento crítico e divergente são estratégias metodológicas também voltadas para um ensino centrado no universo do aluno e para a formação de um cidadão crítico e participativo.

Os planos de aula da disciplina materializam as ideias-chave não apenas como conteúdo programático, mas, também, como proposta metodológica. As concepções e as práticas pedagógicas das professoras cursistas eram constantemente exploradas, e as discussões eram sempre estimuladas durante as aulas, por intermédio de atividades práticas (experimentação, apresentação de seminários, análises de casos etc.) e dinâmicas variadas (trabalhos individuais e em grupos, dentro e fora de aula, debates etc.). Ademais, a interdependência e integração entre as ideias-chave concretizam o que seu idealizador denomina de ensino centrado nos fenômenos.

As ideias-chave mencionadas sintetizam as perspectivas supostamente vanguardistas contempladas pela disciplina Teoria Pedagógica e Produção em Ciências e Meio Ambiente. A premissa adotada no presente estudo é de que a disciplina investigada poderia proporcionar uma formação diferenciada e inovadora às professoras cursistas.

\section{Metodologia da pesquisa}

Para atingir o objetivo e responder às questões apresentadas para o presente estudo, optou-se por um enfoque predominantemente qualitativo, desenvolvido por intermédio de um estudo de caso, na medida em que se circunscreve à observação detalhada de um determinado contexto e de um grupo específico de pessoas (BOGDAN; BIKLEN, 1994). Para os autores, a pesquisa qualitativa caracteriza-se por coletar os dados no "ambiente natural", por meio "do contato direto do pesquisador com a situação estudada", apresentá-los de maneira descritiva e desvendar a "perspectiva dos participantes” (BOGDAN; BIKLEN, 1994, p. 47).

O "ambiente natural" do presente estudo é um curso de formação para professoras em exercício (PROESF), especificamente as aulas da disciplina Teoria Pedagógica e Produção em Ciências e Meio Ambiente, sobre as quais se buscou realizar o mínimo de intervenção possível durante a coleta de dados. Com exceção das entrevistas, todas as fontes de dados da pesquisa já existiam na estrutura da disciplina como instrumentos formais de aprendizagem e avaliação.

No semestre em que os dados foram coletados, havia dez classes (aproximadamente, quatrocentas professoras-alunas) cursando Ciências. Contudo, optou-se por restringir a investigação apenas a uma classe, objetivando-se a realização de observações sistemáticas. 
A disciplina Teoria Pedagógica e Produção em Ciências e Meio Ambiente nas seis classes de Campinas eram regidas por três diferentes assistentes pedagógicos. A fim de minimizar uma possível influência dessa variável nos resultados e pela impossibilidade de se observar todas as classes de Campinas sistematicamente, optou-se por analisar apenas uma turma, e foi escolhida a que tinha o melhor relacionamento com a respectiva Assistente Pedagógica.

Portanto, os sujeitos da pesquisa (população) são 13 professoras das séries iniciais do Ensino Fundamental cursistas do PROESF, pertencentes à Turma E do polo de Campinas. Entre essas, entrevistamos uma amostra de três professoras que se propuseram voluntariamente a conceder entrevistas, com o objetivo principal de validar ou não os dados coletados via questionários, questões abertas e observações.

Havia um número maior (cerca de 35) de professoras-alunas na classe investigada, contudo excluímos as que lecionavam exclusivamente na educação infantil, porque não pertencem ao nosso foco de pesquisa.

Os dados foram coletados durante o primeiro semestre letivo de 2006, durante as aulas da disciplina. Foram utilizadas múltiplas fontes e instrumentos de coletas de dados: o Questionário Preliminar, o Questionário Final, a Reflexão Crítica sobre a Prática Pedagógica, a Carta à Profa. Laura, Avaliação da Disciplina e da AP pelas alunas, Entrevistas, Sínteses Temáticas das unidades da disciplina, anotações de observações de aula.

O Questionário Preliminar, utilizado regularmente pela disciplina para coletar as concepções prévias das professoras sobre ensino de Ciências, tinha como objetivo: problematizar os conteúdos a serem desenvolvidos durante o semestre, avaliar a disciplina e o aproveitamento das professoras. As respostas a esse questionário foram analisadas pela pesquisadora, com o objetivo de investigar quais as concepções e práticas sobre ensino de Ciências no início do curso e qual a formação anterior em Ciências dessas docentes. Para se adequar a essa nova finalidade, foram acrescentadas, ao formato original do Questionário, algumas questões, enquanto outras foram aperfeiçoadas ou adaptadas, mas sem alterar sua essência.

O Questionário Preliminar constitui-se de questões predominantemente fechadas ou mistas, isto é, as questões dão a possibilidade de uma outra resposta caso a entrevistada não concorde com nenhuma das alternativas.

O teste-piloto do Questionário Preliminar foi aplicado a três professoras de Ensino Fundamental, que não cursavam o PROESF, algumas semanas antes do início da investigação, para averiguar a inteligibilidade das questões acrescentadas. Duas questões foram modificadas devido aos resultados do teste-piloto.

Ainda no primeiro dia de aula, a pesquisa foi apresentada em linhas gerais à turma e as professoras cursistas concordaram em participar da mesma, sendo informadas que não seriam identificadas e que a pesquisadora assistiria às aulas juntamente com elas durante todo o semestre. Foi solicitada a adesão voluntária de professoras que gostariam de ser entrevistadas na semana seguinte, durante as aulas de Ciências. As voluntárias deveriam, obrigatoriamente, lecionar nas séries iniciais do Ensino Fundamental e serem efetivas no cargo, considerando que havia, na classe, muitas professoras que atuavam na educação infantil (que não é nosso foco de pesquisa) ou lecionavam eventualmente, ou como auxiliares (o que inviabilizaria os questionamentos sobre a prática docente).

Foram entrevistadas, portanto, na semana seguinte, três professoras da Turma E. As entrevistas centraram-se nas concepções e práticas pedagógicas em ensino de Ciências, bem 
como no aprofundamento das respostas assinaladas ou explicitadas no Questionário Preliminar. O uso desse instrumento teve como objetivos: verificar as concepções e práticas declaradas dessas professoras em Ciências; e aprimorar o Questionário Preliminar como instrumento metodológico, avaliando se elas responderam conscientemente ao questionário e se, de fato, compreenderam as proposições nele contidas.

Anteriormente às entrevistas, as professoras assinaram uma declaração de que as estavam concedendo livre e espontaneamente, na qual se estabelecia, ainda, o compromisso da pesquisadora de não identificá-las na divulgação da pesquisa.

Após a conclusão das entrevistas iniciais, a pesquisadora passou a acompanhar as aulas da classe pesquisada para observar a concretização do curso, sendo que conhecia previamente apenas o planejamento geral do mesmo e os planos de aula e roteiros de atividades. Essas observações foram sistematizadas em um diário de campo.

Ao longo da disciplina, ao final de cada unidade temática, as professoras cursistas produziram sínteses temáticas individuais escritas. Essa foi uma das formas pelas quais tiveram seu aproveitamento da disciplina avaliado. As sínteses desenvolvidas pelas professoras que foram entrevistadas também são objeto de análise da presente pesquisa.

Ao final da disciplina, as professoras cursistas tiveram seu desempenho avaliado mediante três instrumentos: o Questionário Final, o Resgate Crítico da Prática Docente e a Carta à Profa. Laura. Esses instrumentos foram, também, parâmetros para a avaliação da própria disciplina.

O Questionário Final consiste em confirmar ou não as respostas dadas ao Questionário Preliminar, justificando-as.

O Resgate Crítico versa sobre as contribuições da disciplina para a prática das professoras respondentes (o que já faziam, o que pretendem fazer, e o que não mais pretendem fazer em termos de ensino de Ciências, após terem cursado a disciplina).

$\mathrm{Na}$ Carta à Profa. Laura, as professoras cursistas deveriam sugerir melhorias nas aulas de uma colega fictícia, sobre a qual, no decorrer da disciplina, leram um texto descritivo da prática docente da mesma ${ }^{4}$.

As professoras alunas opinaram ainda, de forma escrita, sobre os acertos e falhas da disciplina e avaliaram o desempenho da Assistente Pedagógica.

Todos esses instrumentos, que a disciplina investigada utilizou como formas de avaliar o processo de ensino-aprendizagem das professoras cursistas e da própria disciplina, foram fontes de dados da presente investigação.

Além disso, foram feitas, ao final da disciplina, novas entrevistas com as mesmas professoras voluntárias, a fim de questioná-las a respeito dos reflexos da mesma nas suas concepções e práticas sobre ensino de Ciências.

O Quadro 1 apresenta, de forma resumida, as fontes de dados utilizadas.

\footnotetext{
${ }^{4} \mathrm{O}$ texto supracitado é parte do livro FRACALANZA, H.; AMARAL, I. A.; GOUVEIA, M. S. F. O ensino de ciências no primeiro grau. São Paulo: Atual, 1986. Disponível em: <http://www.fe.unicamp.br/formar1/revista/ N000/pdf/Informacao-Uti-Ensino-de-Ci-1oGrau.pdf>. Acesso em: 04 fev. 2015.
} 
Quadro 1. Fontes de dados da pesquisa

\begin{tabular}{|c|l|}
\hline Público envolvido & \multicolumn{1}{c|}{ Fontes } \\
\hline $\begin{array}{c}\text { População (13 professoras } \\
\text { da Turma E cursistas da disciplina) }\end{array}$ & $\begin{array}{l}\text { - Questionário Preliminar } \\
\text { - Questionário Final } \\
\text { - Reflexão Crítica } \\
\text { - Carta à Profa. Laura } \\
\text { - Avaliação da disciplina e do AP pelas alunas }\end{array}$ \\
\hline $\begin{array}{c}\text { Amostra (3 professoras da Turma E } \\
\text { cursistas da disciplina) }\end{array}$ & $\begin{array}{l}\text { - Entrevista prévia } \\
\text { - Entrevista final da disciplina } \\
\text { - Sínteses temáticas das unidades da disciplina }\end{array}$ \\
\hline Classe pesquisada (Turma E) & - Anotações de observação de aulas ("diário de campo"). \\
\hline
\end{tabular}

Fonte: Elaborado pelos autores.

Optou-se por trabalhar com diversas fontes de dados, que, algumas vezes, se interseccionam, a fim de validar as informações sobre uma mesma concepção e/ou prática declarada docente.

A “análise de conteúdo" foi utilizada como sistemática para tratamento e análise dos dados. Com a utilização das técnicas de análise de conteúdo, pretendeu-se ir além da interpretação espontânea e imediata que pode refletir apenas aspectos da própria subjetividade do pesquisador. Busca-se, ademais, a "superação da incerteza" (“será a minha leitura válida e generalizável?”) (BARDIN, 2004, p. 25) e o enriquecimento da interpretação.

As técnicas de análise de conteúdo permitem identificar aspectos objetivos que possam corroborar a análise subjetiva. "Enquanto esforço de interpretação, a análise de conteúdo oscila entre os dois pólos do rigor da objetividade e da fecundidade da subjetividade" (BARDIN, 2004, p. 7). O autor a define como

[...] um conjunto de técnicas de análise das comunicações visando obter, por procedimentos sistemáticos e objetivos de descrição do conteúdo das mensagens, indicadores (quantitativos ou não) que permitam a inferência de conhecimentos relativos às condições de produção/recepção (variáveis inferidas) destas mensagens. (BARDIN, 2004, p. 37)

Portanto, essas técnicas de análise têm como objetivo central produzir inferências, ou seja, a partir de elementos já conhecidos, obter conclusões, utilizando-se de um processo dedutivo lógico. Como afirma Franco (2005, p. 25):

[...] se a descrição (a enumeração das características do texto, resumida após um tratamento inicial) é a primeira etapa necessária e se a interpretação é a última fase, a inferência é o procedimento intermediário que vai permitir a passagem explícita e controlada da descrição à interpretação (grifos do autor). 
Essas técnicas são passíveis de serem empregadas na análise de textos escritos ou, mesmo, de entrevistas orais, após transcritas. Por isso, são adequadas para a análise dos dados coletados no presente estudo.

Segundo Franco (2005, p. 57), “a criação de categorias é o ponto crucial da análise de conteúdo.” A autora define a categorização como: “uma operação de classificação de elementos constitutivos de um conjunto, por diferenciação seguida de um reagrupamento baseado em analogias, a partir de critérios definidos" (FRANCO, 2005, p. 57).

Comparou-se, por meio de categorias determinadas a priori, as mensagens produzidas por diferentes emissores (todas as professoras entrevistadas, por exemplo), e, ainda, as mensagens produzidas por um mesmo emissor em diferentes ocasiões (entrevista concedida por uma mesma professora antes e após ter cursado a disciplina, por exemplo).

O tratamento dos dados passou por três estágios, a seguir resumidos:

- Descrição e análise (segundo cada categoria) dos resultados obtidos por intermédio de cada um dos instrumentos de coleta;

- Comparação (segundo cada categoria) dos resultados obtidos por intermédio dos diversos instrumentos de coleta;

- Discussão e interpretação dos resultados, por intermédio da integração das diversas categorias e instrumentos.

Pela relevância e importância do papel que desempenham na estruturação e desenvolvimento da disciplina, as sete ideias-chave (programáticas e metodológicas) da própria disciplina investigada constituíram a base das categorias de análise a serem adotadas na pesquisa, a fim de se detectarem as mudanças e permanências nas concepções e práticas declaradas sobre ensino de Ciências das professoras investigadas. As sete ideias, anteriormente mencionadas neste capítulo, foram sintetizadas pela pesquisadora em três grandes categorias, para fins de análise dos dados, a seguir mencionadas e brevemente explicadas:

1. Ciência como atividade humana: subjetividade e limitações na atividade científica; relações entre senso comum e conhecimento científico; relações entre Ciência, Tecnologia e Sociedade; historicidade do conhecimento científico;

2. Ambiente integrado e em contínua e permanente transformação: interação, integração e equilíbrio dinâmico das transformações no ambiente terrestre; universalidade das transformações e uniformidade dos seus processos; indissociabilidade entre os mundos natural e humanizado; interdisciplinaridade curricular;

3. Ensino centrado no universo do aluno: incorporação dos universos físico, social, cultural e psicológico do aluno (exploração do cotidiano do aluno); estímulo ao desenvolvimento do pensamento crítico e divergente; problematização dos conteúdos e elaboração de hipóteses; interdisciplinaridade curricular.

Nas categorias 2 e 3, foram incluídas algumas dimensões que, embora não apresentem, à primeira vista, uma correlação direta com as respectivas denominações, representam atributos genericamente a elas correlacionáveis. É o caso de "interdisciplinaridade curricular", que pode tanto se enquadrar no âmbito dos conteúdos programáticos específicos (categoria 2), quanto no âmbito pedagógico-metodológico (categoria 3).

É o caso, também, do desenvolvimento do pensamento crítico e divergente, que não se enquadra, exclusivamente, na perspectiva do "ensino centrado no aluno", mas se admite que essa seja uma associação possível e recomendável. E, finalmente, a "indissociabilidade entre 
os mundos natural e humanizado", que é tomada como uma das expressões de um ambiente integrado.

Outras categorias emergentes foram formuladas em consonância com o que os dados mostraram. Portanto, pretendeu-se evidenciar, ainda, aspectos do material coletado que não couberam nas categorias elencadas a priori, a fim de que não se perdesse sua riqueza.

\section{Análise dos resultados}

Ao início da disciplina, o grupo de professoras pesquisadas tinha concepções e práticas declaradas sobre o ensino de Ciências mais avançadas do que se esperava encontrar, contrariando o que aponta a literatura e os próprios pressupostos da disciplina pesquisada. Estas concepções e práticas avançadas parecem ser decorrentes dos sistemas de ensino municipais em que trabalham, que têm currículos próprios e inovadores (frequentemente impostos às professoras), investem em formação continuada, trabalho coletivo e, de certa forma, apoiam inovações pedagógicas (embora algumas delas reclamem da escassez de materiais). Mas diversas dessas concepções também eram fruto da apreensão de um jargão educacional corrente, sem a devida compreensão de todos os aspectos envolvidos em determinada temática.

Por outro lado, essa familiaridade inicial, ainda que aparente, com os aspectos inovadores da disciplina, atenuaram o possível impacto, tanto positivo quanto negativo, que a mesma poderia ter provocado entre as professoras-alunas.

Mesmo considerando que as professoras já tinham e praticavam algumas noções a respeito das temáticas tratadas, a disciplina investigada parece ter promovido mudanças bastante perceptíveis nas concepções e práticas declaradas das professoras participantes, sobretudo em relação às ideias-chave Ensino centrado no universo do aluno e Ciência como atividade humana. A primeira parece ter sido a mais impactante, pois todas as professoras-alunas relataram mudanças em relação a esta ideia-chave. Ela, provavelmente, alcançou tal sucesso por ter encontrado eco em algumas concepções e práticas com as quais as professoras já estavam familiarizadas, mas sem que houvessem refletido profunda e teoricamente sobre o significado e a importância dessas estratégias para a aprendizagem dos alunos. Por sua vez, em relação à Ciência como atividade bumana, foram descritas mudanças por, aproximadamente, metade das professoras-alunas. Uma provável explicação é que esta era uma ideia relativamente nova, mas acessível à maioria das professoras pesquisadas, pois não dependia de outros conhecimentos.

Ao contrário, a ideia-chave Ambiente integrado em contínua e permanente transformação parece ter sido a menos compreendida pelas professoras participantes, pois a apreensão desta noção dependia de conhecimentos amplos dos diversos campos das Ciências Naturais, que as professoras das séries iniciais, geralmente, não dominam em virtude de sua formação generalista. Além disso, a carga horária destinada à disciplina foi insuficiente para permitir uma formação mais adequada quanto a estes conteúdos, sobretudo, por envolver uma síntese complexa da dinâmica da natureza.

O mesmo aconteceu com a noção de educação ambiental. Apesar de terem sido detectados alguns avanços em relação a esta noção após as professoras cursarem a disciplina, a compreensão ampla de todos os aspectos implicados nas ideias sobre a mesma, disseminadas pela disciplina, demanda um entendimento aprofundado da dinâmica ambiental contida na ideia- 
chave Ambiente integrado em contínua e permanente transformação, e da interdisciplinaridade interna às Ciências Naturais. Os resultados mostraram que as professoras pesquisadas definem, como interdisciplinaridade, o que, na verdade, se trata de multidisciplinaridade articulada, sobre a qual elas fazem referência sempre no âmbito externo às Ciências Naturais, ou seja, a integração entre Ciências e as demais disciplinas.

Portanto, considerando-se a indissociabilidade entre forma e conteúdo, ainda que as professoras compreendam e dominem algumas estratégias metodológicas de ensino (como se evidenciou pela adesão à ideia-chave Ensino centrado no universo do aluno), essas ficam comprometidas pelas deficiências no campo dos conteúdos específicos. E a falta de domínio dos conteúdos faz com que as professoras tenham dificuldade em elaborar e introduzir estratégias de ensino inovadoras, por isso, a maior expectativa das docentes em relação aos cursos de formação em serviço é de que eles forneçam novas metodologias de ensino.

Contudo, embora as professoras, ao final da disciplina, se encontrassem confusas e contraditórias a respeito de parte destas ideias (inclusive, algumas relacionadas às duas ideias-chave mais impactantes), conclui-se que a problematização promovida pela disciplina e os elementos teórico-práticos por ela proporcionados deflagraram um processo de mudança conceitual que poderá levar a uma futura evolução nas concepções e práticas dessas professoras de modo geral. Verificou-se, ainda, que as professoras cursistas passaram a valorizar mais o ensino de Ciências, a reflexão sobre a própria prática, e a formação continuada como um caminho para o desenvolvimento profissional.

Contrariamente ao que se esperava no início da pesquisa, as temáticas que mais impactaram as professoras-alunas pesquisadas foram, justamente as mais acessíveis a elas, as que encontraram eco na sua prática anterior, isto é, as ideias-chave que conseguiram aproximar o que elas já faziam do que a disciplina propunha.

Os resultados da presente investigação denotam que as lacunas na formação em conteúdos específicos tornam a professora insegura para: problematizar (isto é, formular questões que, de fato, possibilitem a construção do conhecimento pelo aluno), estar aberta aos questionamentos dos alunos, e conseguir selecionar e desenvolver os conteúdos mais pertinentes sem que, para isso, precise recorrer sempre a livros didáticos. Portanto, estão despreparadas para compreender e desenvolver, com autonomia, inovações programáticas, o que também enfraquece os resultados das inovações metodológicas, para os quais se encontram bem melhor preparadas. Portanto, mesmo que pretendam problematizar os conteúdos a serem desenvolvidos, não os compreendem suficientemente para colocá-los em questão, nem adequá-los ao nível de seus alunos; mesmo que estejam convencidas da importância de trabalhar com hipóteses levantadas pelos alunos, têm dificuldades de lidar com elas e encaminhá-las produtivamente; ainda que queiram fazer aproximações entre as concepções alternativas dos alunos e o saber erudito, não conhecem suficientemente as nuances que separam as duas formas de pensamento; mesmo que queiram praticar uma educação ambiental intimamente integrada aos conteúdos de Ciências, não os compreendem suficientemente para explorar essa perspectiva; ainda que sejam adeptas da interdisciplinaridade, esbarram no desenvolvimento dessa problemática no âmbito interno das Ciências Naturais e das alternativas programáticas que propiciam esse enfoque naturalmente; e assim por diante.

Assim sendo, embora a disciplina Teoria Pedagógica e Produção em Ciência e Meio Ambiente tenha conseguido atingir parte dos seus objetivos, entende-se que, se as professoras-alunas 
tivessem uma formação anterior mais aprofundada em conteúdos científicos ou a disciplina dispusesse de uma carga horária maior para abordá-los, a mesma teria sido mais significativa para as docentes.

\section{Caminhos possíveis para uma formação mais efetiva para as professoras das séries iniciais}

Diante do exposto, fica claro que a formação consistente em conteúdos específicos no Ensino Superior voltado para a preparação do professor polivalente se faz necessária, sendo que uma disciplina de sessenta horas é insuficiente para promover o ensino de metodologias e conteúdos de ensino, além da inserção dos debates contemporâneos sobre Ciência e o ensino de Ciências. Por outro lado, uma formação como geralmente é feita nas licenciaturas para a formação do professor especialista, em que não há integração entre as disciplinas pedagógicas e específicas e nem entre estas últimas, não se apresenta como uma solução para o problema em foco, em virtude da dissociação teoria-prática nessas duas dimensões essenciais. É importante ressaltar, ainda, que a inclusão de disciplinas de conteúdo específico não poderia estar dissociada da respectiva e concomitante metodologia de ensino.

Assim sendo, na formação inicial do professor polivalente, seriam necessárias mais duas ou três disciplinas (dependendo da carga horária) que tratassem dos conteúdos das diferentes disciplinas que são obrigatórias no ensino desta etapa da escolaridade, desenvolvidas de forma integrada, como se espera que as professoras ensinem, mas com maior profundidade conceitual e metodológica se comparadas ao que elas irão ensinar aos seus alunos. Evidentemente, que não se trataria de um receituário pedagógico ou curricular, mas o oferecimento da oportunidade de as professoras vivenciarem enfoques interdisciplinares, que se contrapusessem às suas próprias experiências anteriores.

Em relação às Ciências Naturais, deveriam ser eleitos temas unificadores desta área do conhecimento focados na dinâmica ambiental, que pode ser entendida como um eixo articulador do currículo desta disciplina. Esta foi uma preocupação da disciplina pesquisada, mas que ficou sobrecarregada em relação às demais tarefas a que se propôs. Em síntese, o que se propõe para a formação de professoras para as séries iniciais é:

- formação polivalente em nível Superior;

- abrir espaço significativo nos currículos para disciplinas de conteúdo específico;

- integrar teoria pedagógica, prática de ensino e conteúdo específico nessas disciplinas;

- promover integração entre os conteúdos específicos de cada área curricular (por meio de disciplinas integradoras do conteúdo específico do currículo das séries iniciais como um todo), buscando a interdisciplinaridade;

- nas disciplinas específicas, agregar, aos respectivos conteúdos, a contextualização histórica, educacional e social dos mesmos;

- estimular a ambientalização curricular dentro de uma perspectiva de educação ambiental como um enfoque curricular;

- promover um contato estreito com a escola real, desde o início do curso, como fonte para o processo crítico-reflexivo da prática pedagógica (que o futuro professor não tem). 
Considera-se, ainda, que a formação continuada se faz necessária para suprir essas deficiências em conteúdos específicos de todo o contingente de professoras habilitadas nos moldes atuais para a docência nas séries iniciais. Para atender a esta demanda, seria preciso oferecer cursos, de média ou longa duração, que tratem de conteúdos específicos associados à prática pedagógica.

\section{Referências}

AMARAL, I. A. Currículo de ciências: das tendências clássicas aos movimentos atuais de renovação. In: BARRETO, E. S. (Org.). Os currículos do ensino fundamental para as escolas brasileiras. Campinas: Autores Associados, 1998. p. 201-232.

Currículo de ciências na escola fundamental: a busca por um novo paradigma. In: BITTENCOURT, A. B.; OLIVEIRA JUNIOR, W. M. Estudo, pensamento e criação. Campinas: Ed. Unicamp, 2005. v. 1, p. 83-98.

AUGUSTO, T. G. S. A interdisciplinaridade na educação em ciências: professores de ensino médio em formação em serviço. 2004. 127 f. Dissertação (Mestrado em Educação para a Ciência) - Faculdade de Ciências, Universidade Estadual Paulista, Bauru, 2004.

BARDIN, L. Análise de conteúdo. 3 ed. Lisboa: Edições 70, 2004.

BOGDAN, R. C.; BIKLEN, S. K. Investigação qualitativa em educação: uma introdução à teoria e aos métodos. Porto: Porto Editora, 1994.

BRASIL. Lei 5.692, de 11 de agosto de 1971. Fixa diretrizes e bases para o ensino de $1^{\circ}$ e $2^{\circ}$ graus, e dá outras providências. Diário Oficial da União, Brasília, 12 ago. 1971. Disponível em: <http://www010.dataprev.gov.br/sislex/paginas/42/1971/5692.htm>. Acesso em: 28 out. 2006.

. Lei n ${ }^{\circ}$ 9.394, de 20 de dezembro de 1996. Estabelece as diretrizes e bases da educação nacional. Diário Oficial da União, Brasília, 23 dez. 1996. p. 27833. Disponível em: <https://www.planalto.gov.br/ccivil_03/Leis/L9394.htm>. Acesso em: 20 out. 2006.

Ministério da Educação. Secretaria de Educação Fundamental. Parâmetros curriculares nacionais: ensino fundamental - ciências. Brasília, 1997.

CARVALHO, L. M. A natureza da ciência e o ensino das ciências naturais: tendências e perspectivas na formação de professores. Pro-Posições, Campinas, v. 12, n. 1, p. 139-150, 2001. Disponível em: <http://www.proposicoes.fe.unicamp.br/proposicoes/textos/34artigos-carvalholm.pdf>. Acesso em: 04 fev. 2015.

DELIZOICOV, D.; ANGOTTI, J. A. Metodologia do ensino de ciências. São Paulo: Cortez, 2000. 
DELIZOICOV, N. C.; LOPES, A. R. L. V.; ALVES, E. B. D. Ciências naturais nas séries iniciais do ensino fundamental: características e demandas no ensino de ciências. In: ENCONTRO NACIONAL DE PESQUISA EM EDUCAÇÃO EM CIÊNCIAS, 5. 2005, Bauru. Atas... Bauru: ABRAPEC, 2005. Disponível em: < http://www.nutes.ufrj.br/ abrapec/venpec/conteudo/artigos/3/pdf/p348.pdf>. Acesso em: 04 fev. 2015.

DUCATTI-SILVA, K. C. A formação no curso de pedagogia para o ensino de ciências nas séries iniciais. 2005. 222 f. Dissertação (Mestrado em Educação) - Faculdade de Filosofia e Ciências, Universidade Estadual Paulista, Marilia, 2005.

FRANCO, M. L. P. B. Análise de conteúdo. 2. ed. Brasília: Liber, 2005.

FREIRE, C. Y. Ensino de ciências: o que pensam os professores polivalentes. 2000. 147 f. Dissertação (Mestrado em Educação) - Faculdade de Educação, Universidade de São Paulo, São Paulo, 2000.

MIZUKAMI, M. G. N. Os parâmetros curriculares nacionais: dos professores que temos aos que queremos. In: BICUDO, M. A. V.; SILVA JUNIOR, C. A. (Org.). Formação do educador: avaliação institucional, ensino e aprendizagem. São Paulo: Ed. da UNESP, 1999. p. 46-49.

MONTEIRO, M. A. A.; TEIXEIRA, O. P. B. O ensino de física nas séries iniciais do ensino fundamental: um estudo das influências das experiências docentes em sua prática em sala de aula. Investigações em Ensino de Ciências, Porto Alegre, v. 9, n. 1, p. 7-25, 2004.

PAVAN, F; BRASIL, J. N.; TERRAZZAN, E. A. O que se tem e o que se pode fazer com relação à alfabetização científica e tecnológica nos anos iniciais. In: ENCONTRO NACIONAL DE PESQUISA EM EDUCAÇÃ̃ EM CIÊNCIAS, 6., 2007, Florianópolis. Anais... Belo Horizonte: ABRAPEC, 2007. Disponível em: <http://www.nutes.ufrj.br/ abrapec/vienpec/CR2/p649.pdf >. Acesso em: 04 fev. 2015.

ROSA, C. W.; PEREZ, C. A. S.; DRUM, C. Ensino de física nas séries iniciais: concepções da prática docente. Investigações em Ensino de Ciências, Porto Alegre, v. 12, n. 3 , p. 357-368, 2007.

SILVA, A. V. P. A construção do saber docente no ensino de ciências para as séries iniciais. In: NARDI, R. (Org.). Questões atuais no ensino de ciências. São Paulo: Escrituras, 1998. p. 33-41.

UNIVERSIDADE ESTADUAL DE CAMPINAS. Faculdade de Educação. Apresentação, princípios e objetivos - PROESF. Disponível em: < http:/ /www.fe.unicamp.br/ensino/ graduacao/proesf.html>. Acesso em: 30 maio 2006. 